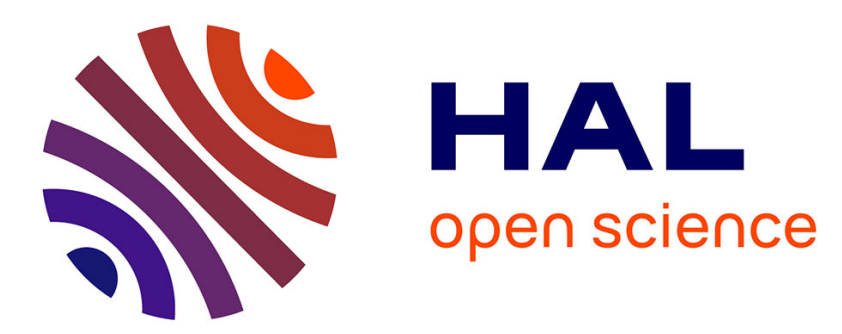

\title{
Using eco-design tools: An overview of experts' practices
} Flore Vallet, Benoît Eynard, Dominique Millet, Stéphanie Mahut, Benjamin Tyl, Gwenola Bertoluci

\section{To cite this version:}

Flore Vallet, Benoît Eynard, Dominique Millet, Stéphanie Mahut, Benjamin Tyl, et al.. Using ecodesign tools: An overview of experts' practices. Design Studies, 2013, 10.1016/j.destud.2012.10.001 . hal-01251846

\section{HAL Id: hal-01251846 https://hal.science/hal-01251846}

Submitted on 3 Dec 2019

HAL is a multi-disciplinary open access archive for the deposit and dissemination of scientific research documents, whether they are published or not. The documents may come from teaching and research institutions in France or abroad, or from public or private research centers.
L'archive ouverte pluridisciplinaire HAL, est destinée au dépôt et à la diffusion de documents scientifiques de niveau recherche, publiés ou non, émanant des établissements d'enseignement et de recherche français ou étrangers, des laboratoires publics ou privés. 


\title{
Using eco-design tools: an overview of experts' practices
}

\author{
Flore Vallet ${ }^{1}$, Benoît Eynard ${ }^{1}$, Dominique Millet $^{2}$, Stéphanie Glatard Mahut ${ }^{1}$, \\ Benjamin $\mathrm{Tyl}^{3}$, Gwenola Bertoluci ${ }^{4}$
}

\author{
${ }^{1}$ Université de Technologie de Compiègne, France \\ ${ }^{2}$ Supmeca Toulon, France \\ ${ }^{3}$ ESTIA Bidart, France \\ ${ }^{4}$ AgroParisTech Massy, France
}

\begin{abstract}
*Corresponding author: flore.vallet@utc.fr
Université de Technologie de Compiègne

Department of Mechanical Systems Engineering

UMR CNRS 7337 Roberval

BP 60319- F60203 Compiègne France

Tel : +33 3442352 44, Fax +33 3445229
\end{abstract}

\begin{abstract}
:
The practice of eco-design requires relating traditional design criteria to new environmental criteria. So far, few studies have investigated the nature and singularities of eco-design. This article provides some elements of response based upon the redesign of a consumer product (disposable razor). The study was conducted by three groups of experienced eco-designers using existing eco-design tools (SIMAPRO, ECOFAIRE, ECODESIGN PILOT). A protocol analysis with a three-level coding of transactions was carried out for this purpose. Two main findings are reported: (1) environmental assessment, solution finding and strategy definition are the activities which differentiate eco-design from design; (2) environmental initial assessment and strategy definition are more heavily influenced by eco-designers' expertise than support from tools.
\end{abstract}

Keywords: ecodesign, protocol analysis, design team, product design.

Understanding the design process has been the subject of multiple works, whose focuses include the evaluation of ideas produced by designers during creative processes (Cross, 1997; Dorst, 2001; Goldschmidt \& Sever, 2009; Yong, Sang, Jung \& Ji, 2009) or the progression of design phases (Valkenburg \& Dorst, 1998; Kruger, 2006; Liikanen, 2009). In order to investigate typical features of design activities, researchers have turned towards analyzing either individual or group design meetings. Collective stakes in design are described according to various viewpoints: the influence of cognitive conflicts on innovation (Badke-Schaub, Golschschmidt \& Meijer, 2007), modelling co-evolution with several actors (Reynen, Dorst \& Smulders, 2009), communication in design teams (Mulet, LopezMesa, Gonzales \& Camelo, 2007).

Eco-design as defined in ISO 14062 (ISO/TR 14062, 2002) is a design approach aiming to reduce the environmental impacts of products and services throughout the whole lifecycle, while assuring similar or improved services to the end customer. The idea is still to meet the consumer's requirements, but in a more sustainable way (Crul \& Diehl, 2009). Designers and design teams are some of the prominent actors playing a central role in the integration of the environment in industry (Akermark, 2003; Lindhal, 2006, Fuad-Luke, 2004). Several conditions must be united if designers are to succeed in this integration, given their lack of knowledge of a complex and multifaceted environmental dimension. Our attention is focused on eco-design methods and tools seen as "vectors of learning" in industry, i.e. allowing designers to improve their individual and collective expertise in eco-design (Millet, 2003). Even though a large number of methods and tools have been created in academia and industry in the past few years, evidence of actual use of existing tools is scarce. There seems to be a real need for stringent analysis to highlight how design activities are supported by eco-design tools (Baumann, Boons \& Bragd, 2002; Lindhal, 2006).

Fargnoli and Kimura compare eight eco-design tools against usability criteria, but do not actually observe the eco-design activity (Fargnoli \& Kimura, 2006). Creative outcomes of the idea generation phase are more likely to be examined in eco-innovation. In (Jones et al., 2001) the influence of input data and choice of method on the quality of outcomes (environmental relevance and originality) is studied, whereas Collado and Ostad-Ahmad-Ghorabi deal with the influence of the level of detail and specificity of environmental information on outcomes (Collado \& Ostad-Ahmad-Ghorabi, 2010). The 
issue of environmental information with regard to how it is managed by professional experts in ecodesign, redesign or innovation is tackled by (Bakker, 1995). All the above illustrate the necessity to better understand the articulation of design phases and the support of eco-design tools in teams.

This article thus aims to gain understanding in the eco-design approach practiced in design teams. We intend to highlight the influence of eco-design tools in resolving problems. How are eco-design tools handled by designers to match the design context? How are shared eco-design vision and strategies constructed in design teams? We provide elements of response through the analysis of the team work of 23 experienced eco-designers working on a same redesign brief and supported by three distinct tools. The following research question is considered: "What is the nature and singularity of eco-design compared to design?"

After defining the activity, methods and tools from a theoretical standpoint (section 1) we pursue our study by a protocol analysis of three design sessions (sections 2 and 3). In section 4 where results are presented, a detailed view of two distinctive phases is provided. The different viewpoints on the problems induced by the tools are examined. Results are discussed in section 5. The conclusions of this work (section 6) fit into a more general framework, whose aim is to characterize the dynamics of learning in eco-design according to the initial expertise (or not) of designers.

\section{Characteristics of the eco-design activity}

Firstly, we intend to review the typical steps of an eco-design approach, and secondly to summarize the contribution of eco-design methods and tools to the design of environmentally-sound products. We close this chapter by stating hypotheses regarding the specific nature of eco-design activities compared to design activities.

\subsection{Steps of the eco-design activity}

Le Pochat et al. (2007) suggest an adaptation of the eco-design process mentioned in (ISO/TR 14062, 2002). Two core activities are emphasized within the conceptual and detailed design phases: environmental assessment and environmental improvement. Environmental assessment aims to evaluate the environmental impacts of an existing product or service, whilst environmental improvement is focused on the search for environmentally friendly solutions. Eco-design tools supporting those two activities are available, complemented by traditional decision making and communication tools. Brezet \& Van Hemel state that, with the integration of environment in design, new activities have appeared in the traditional product development process (Brezet \& Van Hemel, 1997, p. 49). These new activities deal with: the search for environmental information, initial environmental assessment and environmental strategy. The last two seem to differentiate eco-design from traditional design according to Collado \& Ostad-Ahmad-Ghorabi (2010). In order to help companies on a practical level to reduce the environmental impacts of their products, a systematic approach was created (Brezet \& Van Hemel, 1997). Current eco-design tools have certainly been strongly influenced by this early work of systematization. This step-by-step approach embeds seven steps in its initial version, and nine in the latest manual, entitled 'D4S' (Design for Sustainability) (Crul \& Diehl, 2009). Finally three core activities are put forward, namely environmental assessment, solution finding and strategy. Those are defined more precisely in next sub-sections.

\subsubsection{Environmental assessment}

Firstly, environmental assessment is necessary to provide a good initial understanding of the environmental problems caused by the reference product. Secondly, it is meant to evaluate the redesigned product compared with the reference product. For Millet (2003), the initial step of assessment aims to highlight where there are bottlenecks in order to identify relevant focus areas. Following this logic, and since this task has to be processed quantitatively by an environmental expert, it also has to be supported by an expert tool like Life Cycle Assessment (or LCA). Cruhl \& Diehl express a different position, arguing that the results of this first assessment can be obtained qualitatively in experts' focus groups (Crul \& Diehl, 2009). This method appears to be efficient, whilst being far less time consuming than a traditional LCA approach.

However, the environmental quality of products remains closely linked with the notion of service to the customer. Therefore, the functional fulfillment of an eco-product should not be neglected on account of reducing environmental impacts. In order to integrate environmental assessment and functional requirements engineering, Lagerstedt et al. suggest the creation of an 'eco-functional' matrix. This allows the designer to visualize the interrelations between functional criteria (e.g. lifetime, reliability, 
security) and environmental criteria (e.g. size, number of product/year, use of energy, scarce materials) (Lagerstedt, Luttropp \& Linfors, 2003).

The assessment of environmental impacts is a key step of the eco-design process which may not be disassociated from the functional requirements of the product. However, the mechanisms of coupling environmental assessment and functional requirements engineering do not seem to be investigated in depth in available literature. Environmental assessment provides two sorts of useful information: (1) which phases of the life cycle have the greatest impact when assessing an existing product; (2) awareness that no pollution transfer occurred during the environmental improvement phase.

\subsubsection{Solution finding}

The aim of this activity is to create concepts which can lead to environmental improvements. As it is similar to principal solutions generation, it relies on the same kind of creativity techniques: brainstorming, brainwriting or morphological box (Brezet \& Van Hemel, 1997). Creative ideas may be combined in one design thanks to the morphological box. After idea generation, Fussler \& James suggest to start with "harvesting the outstanding ideas" positioned in an Ideas Matrix by the project team (Fussler \& James, 1996, p. 316). The Ideas matrix assesses business value and environmental improvement. Then the top level ideas are mapped onto a spider-web diagram called 'eco-compass', and connections between ideas are created to generate one or several concepts. A redesigned concept of refrigerator may, for example, associate three ideas: (1) an unique plastic material (formed PUR); (2) a separation between fridge and freezer to increase eco-efficiency and reduce maintenance; (3) easy-todisassemble joints to improve end of life (Fargnoli \& Kimura, 2007). Developing environmental solutions can affect multiple aspects of the product including basic product improvement, but also redesign of the product, creating new functions or even making innovations to the system (Brezet, 1997) The following environmental strategy statements which derive from the initial assessment are useful to generate those improvement ideas

\subsubsection{Environmental strategy}

In the traditional design field, a strategy is defined as a "general plan of action" undertaken by a design team and is composed of a sequence of particular activities (Cross, 2008). The notion of environmental strategy includes the various routes which can be followed in eco-design (Brezet \& Van Hemel, 1997, p. 69). It is advisable to choose a relevant combination of eco-design strategies depending on the product, the project and the company situation. Each strategy is developed into a set of guidelines, with the recent addition of ethical and social aspects (Crul \& Diehl, 2009). The seven traditional eco-design strategies proposed by Brezet \& Van Hemel (1997) cover the product lifecycle as follows:

$\mathrm{S}_{1}$ : Low impact material

$\mathrm{S}_{2}$ : Reduction of material use

$\mathrm{S}_{3}$ :Optimization of production techniques

$\mathrm{S}_{4}$ :Optimization of distribution system

$\mathrm{S}_{5}$ :Reduction of impact during use

$\mathrm{S}_{6}$ :Optimization of product lifetime

$\mathrm{S}_{7}$ :Optimization of End of Life systems

Although some strategies are likely to tend in the same way offering a potential synergetic effect, others may be in conflict (Luttropp \& Lagerstedt, 2006). As an illustration of a potential conflict, using recycled materials (as suggested in S1) might significantly decrease the mechanical strength of a part and thus affect the product life time (S6).

Recent research has addressed strategies focused on users' behavior, especially towards energy consuming products. In fact, aiming at eco-efficiency appears to be insufficient if account is taken of how consumers really (mis)use their products. Significant energy loss due to consumers was reported by (Sauer, Wiese \& Ruttinger, 2002). That is why others have expressed new sets of strategies based on user's feedback, persuasion, attractiveness or automatic control (Wever, Van Kuijk \& Boks, 2008; Lilley, 2009; Schmalz \& Boks, 2011).

Using an environmental taxonomy of products, it is possible to choose the most appropriate strategy among several possibilities. Crul and Diehl propose categorizing products into four types thus leading to focused strategies: active or passive (i.e. energy consuming), mobile or immobile (i.e. with transportation during the use phase), requiring consumables, with limited life time (Crul \& Diehl, 2009). Moreover, the same authors point out that environmental targets and strategies have no prescriptive or normative aim, but have simply a pragmatic objective of reducing the problem's complexity: "Remember this is not a precise process but an approximate way of narrowing down the focus for action and reducing the complexity of decision-making" (Crul \& Diehl, 2009 p.51). This is in line with the observations made in a traditional design context by Stempfle \& Badke-Schaub. 
Designers appear to work in a 'quick and dirty' way in order to manipulate data of an acceptable level of complexity and make decisions quite rapidly. This accounts for the alternating phases of widening the problem space (thus increasing the complexity through idea generation) and reducing this space as soon as possible (by comparing and assessing ideas) (Stemfle \& Badke-Schaub, 2002).

The whole range of environmental strategies, which include fostering sustainable behaviours, are expected to be mastered by eco-design practitioners, and should appear in their approach to eco-design problems.

\subsection{Contribution of methods and tools to the eco-design activity}

Before summarizing features of eco-design methods and tools, it is useful to define what is meant by these terms. The word 'eco-design tool' stands for "any systematic means for dealing with environmental issues during the product development process” (Baumann, Boons \& Bragd, 2002). According to Ritzen, the main point is that eco-design tools are supposed to assist designers in their daily tasks, being "artifacts that support product developers with certain considerations or tasks, typically arranged in software or written guidelines" (Ritzen, 2000, p.10). Eco-design needs to be practiced in multidisciplinary teams in industry. It is an efficient way to ensure that all departments of a company contribute to the environmental improvement of products from the early stages of the design process to the market launch (ISO/TR 14062, 2002, p. 7). Cognitive and social aspects of eco-design activity impose the addition of new requirements for methods and tools, as described in the next section.

\subsubsection{Supporting individual and collective learning}

Ritzen introduces the idea that eco-design tools have to support designers in both individual learning and collaborative work as well as enhance communication between company departments. Tools are therefore more helpful in highlighting problems than in solving them (Ritzen, 2000). For Akermark, using a tool gives an opportunity to define a common language, structure and make goals visible to different actors (Akermark, 2003).

Due to the complexity of the eco-design activity, there is a risk of forgetting significant elements during the process. Systematic use of a tool is one way to limit this risk (Akermark, 2003), and hence to increase the confidence designers in their work. Lindhal also underlines the importance of designers' feelings of confidence and satisfaction in achieving work inspired by tools. (Lindhal, 2006). Methods and tools also play an important role in the preservation of the collective memory and company knowledge by creating "know-how back-ups". On an individual level, designers "consciously or subconsciously" associate new methods with former ones, which are never entirely forgotten or abandoned (Lindhal, 2006). Although important for the understanding of the support offered by ecodesign tools, those aspects will not be addressed in this article, but should be considered in future research. Consideration can now be given to how designers' judgment on the use of eco-design tools is influenced by their expertise in eco-design.

\subsubsection{Influence of expertise}

Not all of the various eco-design tools require the same level of environmental expertise. Although it is essential for carrying out any rigourous quantitative assessment, Life Cycle Assessment remains an expert tool. Even though LCA has been progressively introduced into large companies, it is still rarely implemented in small and medium enterprises (SMEs) due to lack of time and the technical and human means to disseminate the method (Le Pochat, Bertoluci \& Froelich, 2007). More generally, environmental assessment tools are reserved for experts, who are supposed to guarantee the relevance of both results and interpretations. By contrast, improvement tools such as guidelines or eco-design manuals are less demanding in terms of environmental expertise, but they present the disadvantage of being too general (Le Pochat, Bertoluci \& Froelich, 2007).Thus, a successful integration of the environmental dimension relies on the presence of an expert or an environmental group in active collaboration with design teams and the company's top management (Millet, 2003). So far, the issue of choosing eco-design tools in compliance with the users' level of expertise has been poorly investigated. One possible explanation for this is that environmental experts who design tools, are unaware of nonexperts' difficulties (Le Pochat, Bertoluci \& Froelich., 2007). Jones (2003) suggests two ideas based on his observations of practitioners using eco-innovation tools:

- less experienced designers tend to follow the given process carefully, 
- $\quad$ more experienced designers do not follow any systematic approach and reason by intuition as individuals; within a team, they feel a deeper need to rely on a structured process to achieve better group performance.

Considering those issues, the objective is to validate the ability of experts to environmentally design and evaluate new concepts. This leads to formulate two hypotheses.

\subsection{Hypotheses: main eco-design activities}

The importance of three core eco-design activities has been underlined in the literature survey. In the next sections these will be referred to as 'eco-activities'. As demonstrated in the case of PSS in Sakao, Paulsson \& Mizuyama (2011), our first assumption deals with the expected nature of the eco-design process when compared to a traditional design process.

H1: "The eco-design process has a similar structure to a traditional design process "

Eco-activities are supported by existing eco-design tools. The second assumption of this paper is that the use of eco-design tools by practitioners will 'reveal' eco-activities. Significant differences are expected to be observed between eco-activities, either in time spent or in content. Differences with traditional design activities are expected to be noticeable.

H2: "All activities are not equally important in time spent. Eco-design can be differentiated from design when the more important activities are considered". The intention is to empirically investigate $\mathrm{H} 1$ and $\mathrm{H} 2$ to clarify the nature and potential singularities of eco-design activities thanks to the following research set-up.

\section{Research method}

We chose to carry out participant observation in an academic context to match our theory driven research question. The controlled conditions of a lab experiment allow us to focus on the eco-design activity without the bias of real life constraints. This kind of enquiry is mostly supposed to neutralize the real-world influence of other business constraints and trade-offs. In order to obtain fine tuned insights as well as quantitative elements of comparison, a verbal protocol analysis was conducted on three design meetings (Gero \& Mc Neill, 1998). Coding options are explained in sections 2.3 and 2.4. This is a typical 'small scale experiment' as characterized by Cash et al. (2012). It has to be noted that a design experiment should, in theory, include one control group (Blessing \& Chakrabarti, 2009). This would be a team that is given the same assignment but no tool. This choice was not made at the time where the research was set up, and this limitation is reflected on in 4.3.

\subsection{Choice of eco-design tools}

The experiment was originally implemented with four eco-design tools: the guides ECOFAIRE, ECODESIGN PILOT, INFORMATION INSPIRATION and the LCA tool SIMAPRO. Due to a poor audio recording, the INFORMATION INSPIRATION transactions could not be taken into consideration in this article; however the whole set of solutions created by the four groups can be found in (Vallet, Millet \& Eynard, 2009; 2011).

The four tested tools are classified after Knight \& Jenkins (Knight \& Jenkins, 2009), see Table 1. They describe three broad categories depending on the lifecycle approach.

1. Guidelines: broad supports of the whole life cycle;

2. Checklists: "providing in-depth, but narrow application at selected stages of the product development process or lifecycle";

3. Analytical tools combining a systematic, detailed vision over the whole lifecycle.

The tested tools (see Box 1) were selected in a focus groups of eco-design experts. SIMAPRO, an expert tool of quantitative Life Cycle Assessment was introduced amongst three eco-design guides, which are non-expert tools. Despite its different nature, it is nevertheless a reference tool acknowledged by practitioners, which accounts for its presence in the protocol. Besides, we are interested in observing experienced eco-designers' capacity to use an LCA tool in early design phases, when very little data is available to them.

Table 1: Characterization of selected eco-design tools

\begin{tabular}{|c|c|c|c|c|}
\hline $\begin{array}{c}\text { Name of tool } \\
\text { /author/Date } \\
\text { published }\end{array}$ & Category & Language & Addressed to & Objectives \\
\hline $\begin{array}{c}\text { ECOFAIRE } \\
\text { /SEM }\end{array}$ & Guideline & French & $\begin{array}{c}\text { Engineering } \\
\text { designers, }\end{array}$ & $\begin{array}{c}\text { Introduction to eco-design } \\
\text { Diagnosis/ First }\end{array}$ \\
\hline
\end{tabular}




\begin{tabular}{|c|c|c|c|c|}
\hline $\begin{array}{c}\text { Pays de } \\
\text { Loire/2008 }\end{array}$ & & & $\begin{array}{c}\text { Industrial designers, } \\
\text { Research department, } \\
\text { Marketing ... } \\
\text { Teachers, Students. }\end{array}$ & $\begin{array}{c}\text { environmental assessment } \\
\text { Solution finding/Evaluating } \\
\text { solutions } \\
\text { Communication }\end{array}$ \\
\hline $\begin{array}{l}\text { INFORMATION } \\
\text { INSPIRATION } \\
\text { /Loughborough } \\
\text { University/2005 }\end{array}$ & Guideline & English & Industrial designers & $\begin{array}{l}\text { Introduction to eco-design } \\
\text { Environmental strategies } \\
\text { Examples of eco-products }\end{array}$ \\
\hline $\begin{array}{l}\text { ECODESIGN } \\
\text { PILOT } \\
\text { /TU Wien/2001 }\end{array}$ & Guideline & $\begin{array}{c}10 \\
\text { languages }\end{array}$ & $\begin{array}{c}\text { Designers, Industrial } \\
\text { designers, } \\
\text { Manufacturers, } \\
\text { Environment } \\
\text { managers. }\end{array}$ & $\begin{array}{l}\text { Introduction to eco-design } \\
\text { Environmental strategies } \\
\text { Tracks for environmental } \\
\text { improvement }\end{array}$ \\
\hline $\begin{array}{c}\text { SimaPro 7.0/ } \\
\text { Pré Consultants }\end{array}$ & Analytic & English & $\begin{array}{l}\text { Environmental } \\
\text { experts }\end{array}$ & Environmental assessment \\
\hline
\end{tabular}

\subsection{Experimental protocol}

This study is part of a set of experiments focusing on the redesign of various types of products, among which an outdoor lighting system (Tyl et al., 2010) and a disposable manual razor. The last case of 'consumable product' is developed in this paper. The design brief given to the participants is illustrated in Figure 1. Given the limited duration of the test (1.5 hour), it seems appropriate to propose a simple consumer product requiring no distinctive expertise.

\section{The BARBARAZ Case}

The BARBARAZ company produces disposable manual razors for the European market.

Strong criticism of disposable products has led this company to get involved in a global eco-design approach on their products.

That is why you, as eco-design experts, have been called on to analyze their reference product in environmental terms and to make concrete and progressive propositions for improvement.

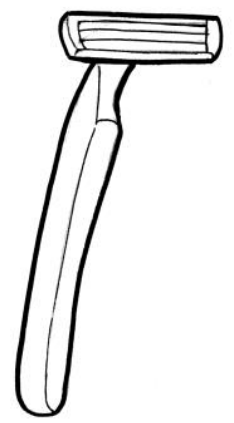

Figure 1: Excerpt of the redesign brief of a disposable razor

The participants and teams leaders belong to a group of researchers in Eco-design of systems for Sustainable Development (EcoSD) holding a seminar three times a year. The experiment takes place during one of the seminars dedicated the use of eco-design tools. Four meeting rooms are equipped with audio recording systems on that purpose. The experimenter leads one of the groups. Participants are considered as experts in eco-design. In fact their experience in eco-design ranges from one year to approximately 15 years (Mean: 6.30; $\mathrm{SD}=3.75$ ). They are divided into two categories: engineers in industry or consultancy (25\%) and researchers (75\%). Dreyfus, cited by (Eder, 2009), defines seven levels of expertise (from novice to visionary). After examination of behaviours and communicative acts during the experiment, it can be assumed that three categories of expertise are represented among the participants: competent, proficient, and expert. However, the 23 participants were placed into four groups in order to even out the expertise in eco-design. Subsequently the word 'expert' will be used for more convenience. The ability to implement a Life Cycle Assessment tool such as SIMAPRO is investigated just before the design meeting, showing that $74 \%$ of the subjects (equally spread across the groups) are able to practice LCA. All groups included at least one woman, and mixed industrial and academic practitioners. The experiment was conducted in French.

The rationale for enrolling experienced eco-designers is on the one hand to collect a rich sample of information within a limited time and on the other hand to take advantage of their reflective ability. But this choice also embeds an identified bias: experts might not require tools if their expertise is sufficient with a simple assignment. Participants were thus involved in three tasks with the objective of making comparative evaluations of the eco-design process and results:

1. Test a tool.

2. Give feedback on process through a first e-mailed questionnaire $\mathrm{Q}_{1}$ (responding rate $74 \%$ ). 
3. Give feedback on their group's creative outcomes and on other groups' through a second web questionnaire $\mathrm{Q}_{2}$ (responding rate $56 \%$ ).

The experiment is divided into three main steps (Table 2): presentation and carrying out of the design meeting, followed by feedback questionnaires after a week and 1.5 months, completed by an overall presentation by the experimenter to the participants three months later. Each participant was contacted individually to provide reflections on the process and on the generated concepts. In order to characterize the eco-design process, they were asked to rank tools on a five-point Likert scale regarding multi-disciplinarity, usability (i.e. easiness to use and learn), compatibility with few input data and time efficiency, see (Lindhal, 2005). Free comments could be added. Through Q2, subjects had to rank each generated idea on an identical type of Likert scale against: originality and environmental performance, see (Jones et al., 2001).

Table 2: Agenda of the experimental protocol

\begin{tabular}{|c|c|c|}
\hline INPUTS & DETAIL OF PHASE & OUPUTS \\
\hline $\begin{array}{l}\text { Powerpoint presentation of } \\
\text { tools and design brief }\end{array}$ & $\begin{array}{c}\text { Framing } \\
30 \text { min, collective }\end{array}$ & - \\
\hline $\begin{array}{l}\text { Design Brief (printed format) } \\
\text { Paperboard sheets, felt tip pens, } \\
\text { Personal stationary authorized }\end{array}$ & Design Meeting (1h30) & $\begin{array}{c}\text { Completed paperboard sheets, } \\
\text { AND/OR files (ppt, word, } \\
\text { SIMAPRO) } \\
\text { Audio recordings }\end{array}$ \\
\hline & Collective debriefing (15 min) & \\
\hline $\begin{array}{l}\text { Q1 Questionnaire } \\
\text { Sent by e-mail }\end{array}$ & $\begin{array}{c}\text { Feedback of participants on } \\
\text { tools }(D+7)\end{array}$ & Completed Q1 questionnaire \\
\hline Q2 Web-questionnaire & $\begin{array}{l}\text { Feedback of participants on } \\
\text { generated concepts }(D+45)\end{array}$ & Completed Q2 questionnaire \\
\hline $\begin{array}{c}\text { Powerpoint Presentation } \\
\text { of results (Q1 and Q2) }\end{array}$ & $\begin{array}{c}\text { Feedback of researcher on first } \\
\text { observations } \\
(1 \mathrm{~h})(\mathrm{D}+90)\end{array}$ & $\begin{array}{c}\text { Reactions from participants } \\
\text { Confirmations/Perceptive } \\
\text { offsets }\end{array}$ \\
\hline
\end{tabular}

Every session was transcribed according to the simplified notation suggested in (Mc Donnell \& Lloyd, 2009 , p.7). Each line is associated with an intention of the designer identified by the coder. This division was refined throughout the coding process. Table 3 below presents a summary of the observation conditions.

Table 3 : Summary of observation conditions of the three groups

\begin{tabular}{|l|l|l|}
\hline Groups & Duration of the observation & Number of lines transcribed \\
\hline SIMAPRO & $1 \mathrm{~h} 20$ & 182 \\
\hline ECOFAIRE & $1 \mathrm{~h} 24$ & 550 \\
\hline ECODESIGN PILOT & $1 \mathrm{~h} 27$ & 537 \\
\hline Participants & Experts : 75\% academia / 25\% industry \\
\hline
\end{tabular}

\subsection{Coding model}

Since the coding model is meant to analyse a collective eco-design session, it should reflect the collaborative dimension of work as well as the specific features of the activity (namely initial environmental assessment and strategy). Three models in Table 4 retain our attention. Bakker's coding model is partially suitable with regard to eco-design steps; however it has to be completed for it was used for analyzing individual working sessions (Bakker, 1995). The second model for traditional design sessions by Stemfle \& Badke-Schaub (2002) is inspired by the product development reference steps of Pahl et al. (2007). Its main interest is that it explains both the 'Content' (the process of solving of the task itself) and the 'Process' (the management of the task within the design team).The third model focuses on the types of interactions between members of a design team (Prudhomme, Pourroy \& Lund, 2007). It is helpful in clarifying the definition of the category 'Assessment of solutions'. Our final coding proposition results from a combination of models from (Bakker, 1995) and (Stemfle \& Badke-Schaub, 2002). It is completed with a 'Tool' (abbreviated T) category to emphasize moments where tools are mentioned during group transactions. 


\section{ECOFAIRE}

The French program ECOFAIRE was organized and conducted by SEM Pays de Loire in collaboration with the environment consultancy EVEA between 2006 and 2008 (ECOFAIRE, 2008). This program seeks to "favor and facilitate the development of environmentally friendly products". A collaborative study was carried out with companies, industrial and engineering designers. The methodological tool ECOFAIRE is part of this research work. It is composed of two introduction sheets followed by 18 others to be used in five chronological steps: 'Scope and stakes', 'Initial environmental assessment', 'Solution finding', 'Assessment of solutions', 'Results and Communication'. Non-experts users are targeted here, should they belong to industry or to academia.

\section{Information/Inspiration}

The study of the Information/Inspiration web tool originated in a collaborative work between Loughborough University and Electrolux. The first statement was that existing eco-design tools are not appropriate for industrial designers. The synthesis of this study by Lofthouse ended up in the Information/Inspiration prototype (Lofthouse, 2001). It combines in a balanced way traditional eco-design information and examples of eco-efficient product and services. This tool shows two streams accessed via homepage. Within

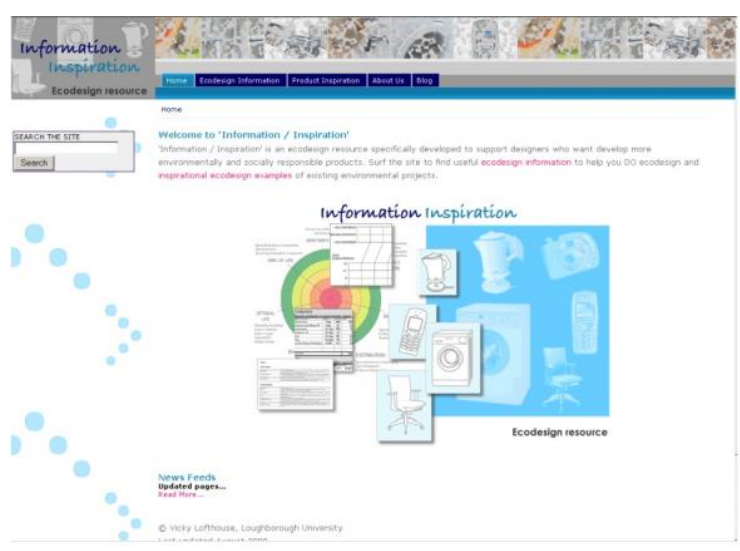
each stream, 'Information' and 'Inspiration' can develop up to three levels of documentation with transversal links. Chronologic architecture was not chosen here, as industrial designers are known to be keen on free navigation.

\section{EcoDesign PILOT}

This tool developed by W. Wimmer et R. Zust is available in the form of a book and a free-access website (Wimmer \& Zust, 2003). PILOT stands for Product, Innovation, Learning and Optimization Tool. It helps identifying the most impacting phases of a product lifecycle and finding practical measures to environmentally improve products. In a project developed by (Pamminger et al., 2007) Ecodesign PILOT is combined to QFD (Quality Function Deployment) and HPO (Holistic Process Optimization) to address respectively stakeholders and production process requirements.

\section{SimaPro 7.0}

This analytical tool developed by PRé Consultant follows the Life Cycle Assessment methodology for assessing potential environmental impacts of a product or service over its life cycle (ISO 14040, 1997). Two main applications can be envisaged: (1) analysis of the contribution of the life cycle stages to the overall environmental load; (2) comparison between products for internal or external communication. The required data on materials and processes can be gathered through questionnaires to data providers or be drawn from the provided full Eco Invent 2.0 database (covering over 4000 processes) (PRéConsultant, 2010). An instance of graphical output by SimaPro is the process tree graph of a disposable

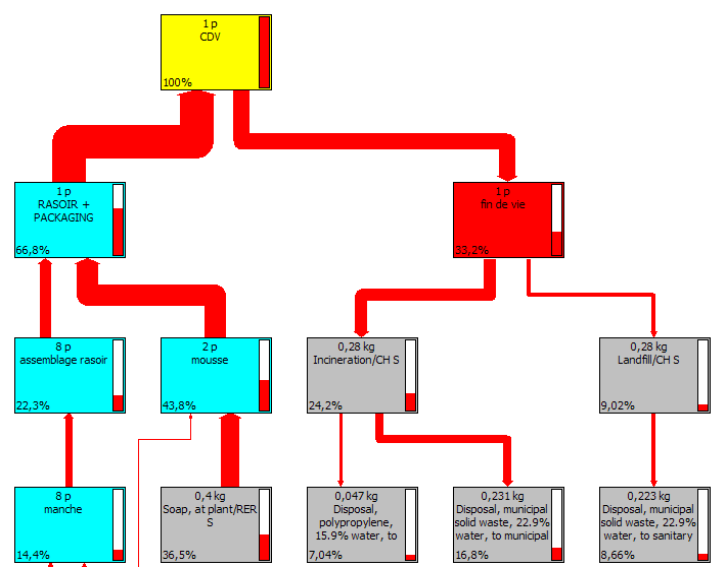
razor for Global Warming Potential, see opposite. 
Table 4: Proposition for a model of collective eco-design activity

\begin{tabular}{|c|c|c|c|c|c|}
\hline \multirow{2}{*}{$\begin{array}{l}\text { BAKKER } 1995 \\
\text { Other }\end{array}$} & \multicolumn{2}{|c|}{$\begin{array}{l}\text { STEMPFLE\&BADKE } \\
\text { SCHAUB } 2002\end{array}$} & \multirow{2}{*}{$\begin{array}{l}\text { PRUDHOMME, } \\
\text { POURROY\&LUND } \\
2007\end{array}$} & \multicolumn{2}{|l|}{ Our proposition } \\
\hline & Content & Process & & Content & Process \\
\hline Analysis & $\begin{array}{l}\text { Goal } \\
\text { clarification }\end{array}$ & Planning & Outside activity & $\begin{array}{l}\text { Goal } \\
\text { clarification }\end{array}$ & Planning \\
\hline $\begin{array}{l}\text { Environmental } \\
\text { Analysis }\end{array}$ & $\begin{array}{l}\text { Solution } \\
\text { Generation }\end{array}$ & & Social relation & $\begin{array}{l}\text { Initial } \\
\text { Assessment }\end{array}$ & Analysis \\
\hline Idea Generation & Analysis & Analysis & $\begin{array}{l}\text { Interaction } \\
\text { management }\end{array}$ & $\begin{array}{l}\text { Environmental } \\
\text { strategy }\end{array}$ & \\
\hline Evaluation & Evaluation & Evaluation & Task management & $\begin{array}{l}\text { Solution } \\
\text { Generation }\end{array}$ & \\
\hline $\begin{array}{l}\text { Environmental } \\
\text { Evaluation }\end{array}$ & Decision & Decision & Opinions & $\begin{array}{l}\text { Assessment of } \\
\text { Solutions }\end{array}$ & Evaluation \\
\hline \multirow[t]{3}{*}{ Modification } & Control & Control & Argumentations & Decision & Decision \\
\hline & & & $\begin{array}{l}\text { Explore and Deepen } \\
\text { arguments }\end{array}$ & Control & Control \\
\hline & & & & Other & Other \\
\hline
\end{tabular}

\subsection{Coding scheme}

Two researchers were involved in an iterative process of coding. First two common sessions of coding (50 lines each) were needed to test the robustness of the coding scheme and refine the model. After the first training phase, a double coding of the three sessions was carried out. The calculated Cohen's Kappa coefficients were: SIMAPRO: 0.93; ECOFAIRE 0.80; ECODESIGN PILOT: 0.83. The coding scheme was judged satisfactory since every coefficient was superior to 0.6 . The final version of the coding scheme is given in Appendices A and B. The detailed analysis of the initial environmental assessment required an additional level of coding in the Content (C)/ Initial Assessment (EI) category. Three sub-categories were created to describe the use phase: conditions of shaving (CD), functionality of shaving (UF) and consumption generated by shaving (CO). These are complemented by three categories related to the lifecycle (usage excluded): extraction of material (M); production (FA), distribution and logistics (T), end of life (FV). The double coding at this level leads to the following satisfactory Kappa coefficients: SIMAPRO: 0.86; ECOFAIRE 0.76; ECODESIGN PILOT: 0.92. An excerpt of transcription and coding for the ECODESIGN PILOT group is provided below (Table 5). In the following section, the results of the coding are exposed firstly as a global overview (3.1), then in detail (3.2).

Table 5 : Excerpt of ECODESIGN PILOT's coded transcript (Part.: Participant ; TL : Team Leader ; F : Fanny ; $J$ : Jonathan)

\begin{tabular}{|c|c|c|c|c|c|c|l|}
\hline Line & Time & Tool & Part. & \multicolumn{2}{|c|}{ Code* } & \multicolumn{1}{c|}{ Dialogue } \\
\hline 234 & & & TL & P & C & & $\begin{array}{l}\text { 'In summary, use very important and end of life, it's the } \\
\text { second thing, isn't it ? }\end{array}$ \\
\hline 235 & & & TL & C & St & & End of life, extraction. Yes, and end of life. \\
\hline 236 & & & F & C & EI & FA & $\begin{array}{l}\text { You have to see because foam doesn't make use of any } \\
\text { brilliant process. It's just thrown out with the water, and } \\
\text { all the products in it. }\end{array}$ \\
\hline 237 & & & J & C & G & & REACH will come up. \\
\hline 238 & & & F & P & O & & \begin{tabular}{l} 
Use soap. \\
\hline 239
\end{tabular} \\
\hline 240 & & TL & C & St & & $\begin{array}{l}\text { So, now extraction and end of life because there is no } \\
\text { reason - }\end{array}$ \\
\hline 241 & & F & C & So & & $\begin{array}{l}\text { So we ought to invent a razor which doesn't need water } \\
\text { or foam. }\end{array}$ \\
\hline 242 & & T & TL & P & Pl & $\begin{array}{l}\text { I'm taking a look at what they suggest (Reads } \\
\text { rapidly). "Washing machine intensive use". }\end{array}$ \\
\hline
\end{tabular}




\section{Results}

\subsection{Global analysis of eco-design sessions}

On a first level we wish to compare the percentage of time dedicated to the generic 'Content' and 'Process' activities in each group (Figure 2). It can be noted that the proportion of 'Process' transactions shows little variation between groups, ranging from $23 \%$ of time for SIMAPRO to $33 \%$ for ECODESIGN PILOT. This Process/Content ratio recalls what was observed by Stemfle \& BadkeSchaub (2002), namely a recurrent proportion of $1 / 3$ Process and $2 / 3$ Content in traditional design studies.

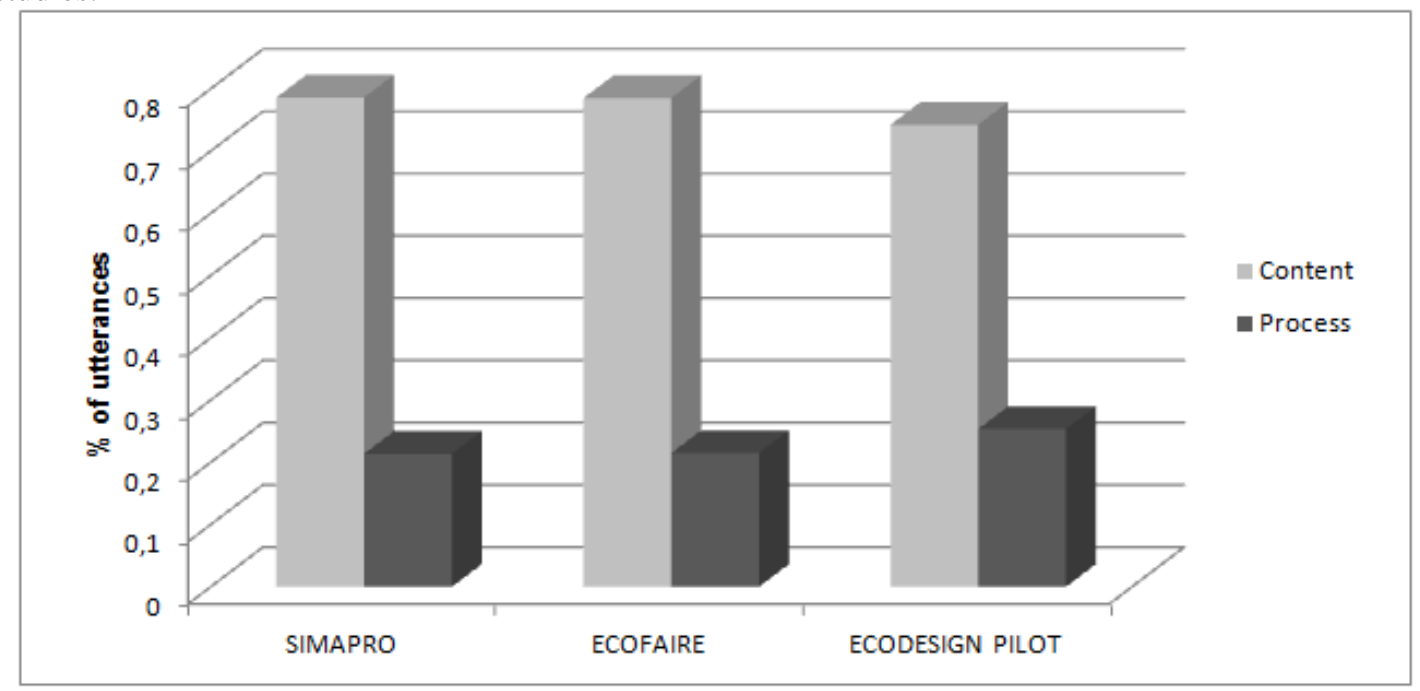

Figure 2: Global time distribution of Content and Process activities

\subsubsection{Global analysis of 'Content' phases}

On a second level the distribution of eight 'Content' sub-categories can be seen in Figure 3. The analysis of the 'Process' level has been carried out, but will not be presented in this paper, which is centred on the core eco-design activities. For SIMAPRO, ECOFAIRE and ECODESIGN PILOT, the percentage of uncategorized transactions (due to incomplete sentences) is respectively 6, 3 and $7 \%$.

As far as the 'Content' work is concerned (Figure 3), few decisions seem to be made in all groups (less than 3\%). A greater proportion of informal and social discussions are observed with ECOFAIRE. Noticeable differences in the management of the five first sub-categories Goal (G), Initial Assessment (EI), Strategy (St), Solutions (So) and Solution Assessment (ES) are reported. Designers of the ECODESIGN PILOT team spend $40 \%$ of their time performing initial assessment of the product. This is $37.5 \%$ more than SIMAPRO and $30 \%$ more than ECOFAIRE. Compared with other teams, SIMAPRO spend twice much time on seeking solutions. Looking back at transcriptions, this result is linked to two different types of solutions under the (SO) heading: elementary concepts (for instance "bamboo handle") and also relative intermediary concepts (such as "Shorten handle by 1/2"). Influenced by the questions in the guide, The ECOFAIRE tool shows longer discussions about the objectives and framing of the study, even as far as calling into question the social necessity for shaving (Line 500): "Saying that, is it a fashion effect, a social effect, a social problem". While remaining qualitative, the discussions using ECOFAIRE spend more time evaluating solutions than is the case for the other tools (+10\% against SIMAPRO;+5\% against ECODESIGN PILOT).

Apart from these differences, a remarkable consistency can be found in the time spent considering 'problem' phases [G, EI, St] versus 'solution' phases [So, ES, D, C]. The three groups actually spend on average $40 \%$ of their time on [G, EI, St] (SIMAPRO : 37\% ; ECOFAIRE : $38 \%$; ECODESIGN PILOT : $45 \%$ ) against an average $34 \%$ on [So, ES, D, C] (SIMAPRO : $39 \%$; ECOFAIRE : $35 \%$; ECODESIGN PILOT: 29\%). Problem and solution oriented activities appear to be balanced in time 


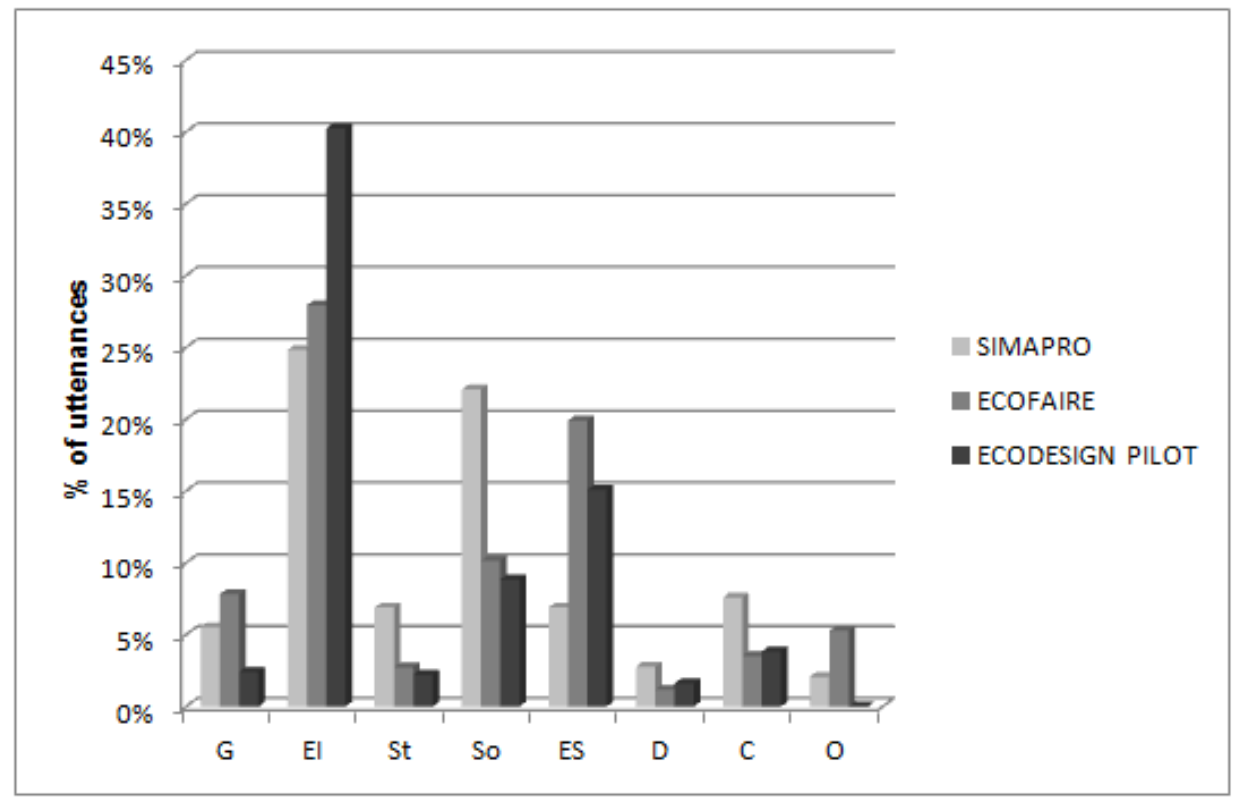

Figure 3: Temporal distribution of 'Content' activities (G : Goal ; EI : Initial Assessment; St : Strategy ; So : Solutions ; ES : Assessment of solutions ; D ; Decision ; $C$ : Control ; O : Other)

\subsubsection{Effective use of tool during 'Content' phase}

Before this is analysed further, it is appropriate to take a close look at the effective use of eco-design tools, as they are the basis of $\mathrm{H} 1$. In fact two distinct patterns are visible. ECOFAIRE is used regularly throughout the whole session. The ECOFAIRE sheets stimulate consideration on various aspects of the environmental problem of shaving. Conversely ECODESIGN PILOT and SIMAPRO are intensively referred to in the second phase of the team work, respectively after 43 and $70 \%$ of the whole session. In order to emphasize the tool contribution during the 'Content' phase, a comparative table of utterances (in \%) is provided: Figure 3 shows this information for the global session and Table 6 shows this for where the tools are effectively used by the groups. No distinction is made with ECOFAIRE, considering it is used though the whole session. When no or slight difference is observed between overall and 'with tool' percentage of utterances, the tool is assumed to have been prevalent in dealing with the corresponding sub-category. According to this, SIMAPRO is effectively helpful for environmental assessment of solutions (ES), Decision (D) and (Control) whereas ECODESIGN PILOT helps with solution finding (So) and assessment of solutions (ES). ECOFAIRE is most efficient in: Initial Assessment (EI) followed by assessment of solutions (ES) and solution finding (So). Table 6 also pinpoints that some activities are neither supported by SIMAPRO nor by ECODESIGN PILOT. That is: Goal Clarification (G), Initial Assessment (EI) (85\% of which is not supported by ECODESIGN PILOT); Environmental Strategy (St). This concerns as well Decision (D) and (Control) for ECODESIGN PILOT. Section 3.2. will focus on the nature of Initial Assessment and Environmental Strategy transactions.

Table 6: Effective 'Content' utterances observed with tools

\begin{tabular}{|c|c|c|c|c|c|}
\hline \multirow{3}{*}{$\begin{array}{c}\text { 'Content' } \\
\text { utterances } \\
(\%)\end{array}$} & \multicolumn{5}{|c|}{ Tool } \\
\hline & \multicolumn{2}{|c|}{ SIMAPRO } & \multirow{2}{*}{$\frac{\text { ECOFAIRE }}{\text { Overall }}$} & \multicolumn{2}{|c|}{ ECODESIGN PILOT } \\
\hline & Overall & With tool & & Overall & With tool \\
\hline $\mathrm{G}$ & 5.5 & 0 & 7.6 & 2.4 & 0 \\
\hline EI & 24.8 & 0 & 28.0 & 40 & 6 \\
\hline St & 6.8 & 0 & 2.8 & 2.2 & 0.8 \\
\hline So & 22 & 4 & 10.0 & 8.8 & 8.6 \\
\hline $\mathrm{ES}$ & 6.8 & 5.5 & 20.0 & 15 & 15 \\
\hline $\mathrm{D}$ & 2.7 & 2.7 & 1.1 & 1.6 & 0.2 \\
\hline $\mathrm{C}$ & 7.5 & 5.5 & 3.5 & 3.8 & 0.2 \\
\hline $\mathrm{O}$ & 2 & 0 & 5.2 & & 0 \\
\hline
\end{tabular}




\subsection{Detailed analysis of eco-design sessions}

In this section, we propose a more detailed analysis of the initial environmental assessment phase, identified as important in 1.1.1. We also examine the stage of formulation of environmental strategy as a means of reducing the complexity of the problem. The analysis of solutions generated by participants is summarized below. Further details can be found in (Vallet, Millet \& Eynard, 2009; 2011).

\subsubsection{Initial environmental assessment}

With a third-level of coding, we can understand the path taken by eco-design experts to address the initial environmental assessment of the product. We note two features:

- Alternation between periods of qualitative and quantitative assessment,

- Environmental and functional viewpoints which overlap and are interrelated, giving an 'ecofunctional' character to the initial assessment.

In support of this last remark, repeated sequences are sought in this phase. We try to identify any preferred associations of reasoning made by experienced eco-designers among the categories Shaving conditions (CD), Functional Unit (UF), Consumptions (CO), Materials (M), Production (FA), Distribution (T) and End of Life (FV). A sequence is determined by a succession of at least two interventions coded under an (EI) heading. Two sequences are separated by an intervention of a different nature, such as Content-Control and Content-Decision. In Table 7, interactions of the first sequence (lines 11-14) with ECOFAIRE are reported, where subjects compare razors for men and those for women. The sequence is composed by: $3 \mathrm{UF}$ and $1 \mathrm{M}$. The sequences are plotted for each tool, exemplified for ECOFAIRE in Figure 4 and included in Table 8. The phases of the life cycle appear under ' $\mathrm{CV}$ ' heading in this table.

The characterization of the phases of the life cycle (alone or combined with $\mathrm{CD}, \mathrm{CO}$, or UF) is predominant with ECOFAIRE, with more than half of the sequences observed in this group (14/22). With ECODESIGN PILOT, $(\mathrm{CO}+\mathrm{CD})$ combinations (alone or in combination with CV) are observed for one third, followed by CD (20\%) and (CO + Life Cycle) (20\%). Although it is difficult to generalize given the small number of SIMAPRO sequences, we note that three of the four categories represented involve an exchange on the conditions of shaving $\mathrm{CD}$.

Overall, across all sessions, the $(\mathrm{CO}+\mathrm{CD})$ sequence alone or in combination appears 11 times, which is about $1 / 4$ of all sequences. This means that to the experts, it is important that both shaving conditions and consumption of water and foam are defined jointly and iteratively. In second position and in the same proportions, we find discussions on the characterization of phases of product life (excluding the use phase) and interdependencies between these phases. These include examining the influence of the choice of material (e.g. polystyrene) and manufacturing (e.g. injection) at the end of product life (e.g. landfill).

Table 7: Excerpt of ECOFAIRE's coded transcript (Part.: Participant; TL:: Team Leader ; B : Bernie; P: Paul)

\begin{tabular}{|c|c|c|c|c|c|c|l|}
\hline Line & Time & Tool & Part. & \multicolumn{3}{|c|}{ Code* } & \multicolumn{1}{c|}{ Dialogue } \\
\hline 11 & & T & B & C & EI & UF & $\begin{array}{l}\text { "Targeted product, not much difference in weight or } \\
\text { material }\end{array}$ \\
\hline 12 & & T & P & C & EI & UF & One more blade, a pivoting head, an ergonomic grip \\
\hline 13 & & T & TL & C & EI & M & Plus one substance : aloe vera \\
\hline 14 & & T & B & C & EI & UF & These finally are very close products \\
\hline 15 & & T & TL & P & C & & We are asked for new concepts, so - \\
\hline 16 & 6 & T & B & C & EI & UF & What are the important impacts?" \\
\hline
\end{tabular}

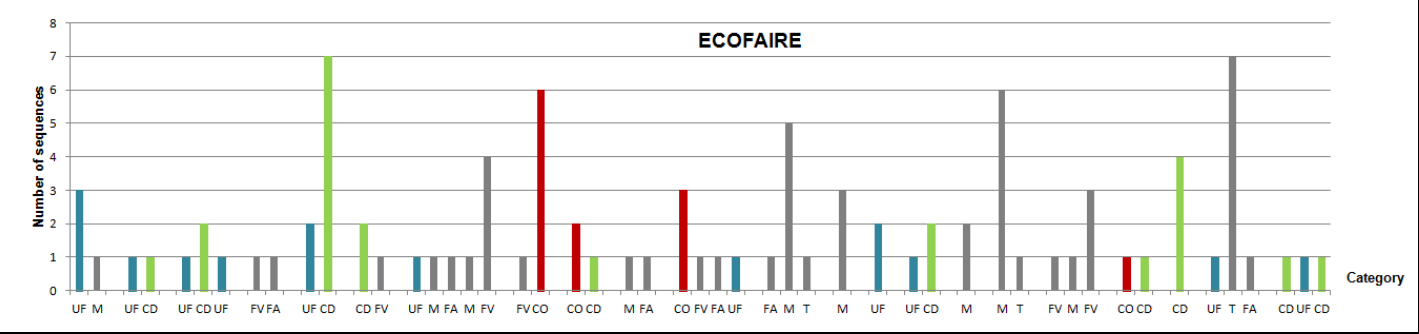

Figure 4: Sequences for Initial Assessment (EI) with ECOFAIRE 
Table 8: Summary of sequences for Initial Assessment (EI); Functional Unit (UF); Consumptions (CO); Shaving conditions (CD); Life Cycle (CV)

\begin{tabular}{|c|c|c|c|c|}
\hline \multirow[t]{2}{*}{ Combinations } & \multicolumn{3}{|c|}{ Number of sequences per tool } & \multirow{2}{*}{$\begin{array}{c}\text { Total number of } \\
\text { sequences/combination }\end{array}$} \\
\hline & SIMAPRO & ECOFAIRE & $\begin{array}{c}\text { ECODESIGN } \\
\text { PILOT }\end{array}$ & \\
\hline UF only & 1 & 1 & & 2 \\
\hline CO only & & & 2 & 2 \\
\hline CD only & & 1 & 5 & 6 \\
\hline CV only & & 7 & 2 & 9 \\
\hline $\mathrm{UF}+\mathrm{CD}$ & 1 & 5 & 1 & 7 \\
\hline $\mathrm{UF}+\mathrm{CV}$ & & 3 & 2 & 5 \\
\hline $\mathrm{CO}+\mathrm{CD}$ & & 1 & 7 & 8 \\
\hline $\mathrm{CD}+\mathrm{CV}$ & 2 & 1 & & 3 \\
\hline $\mathrm{CO}+\mathrm{CV}$ & & 2 & 5 & 7 \\
\hline $\mathrm{CO}+\mathrm{CD}+\mathrm{CV}$ & 2 & & 1 & 3 \\
\hline $\mathrm{UF}+\mathrm{CO}+\mathrm{CV}$ & & 1 & & 1 \\
\hline $\begin{array}{l}\text { Total number } \\
\text { of sequences } \\
\text { per tool }\end{array}$ & 6 & 22 & 25 & 53 \\
\hline
\end{tabular}

\subsubsection{Definition of an eco-design strategy}

Elements of environmental strategy are referred to as 'levers' in the SIMAPRO group, and 'axis' in the ECOFAIRE group. These strategies are mentioned by the teams in the context of shaving (Table 9). After extracting each strategy statement from the transcripts, each is repositioned with the strategies of section 0 . The statement of these strategies is a crucial stage of the process and a basis for seeking creative solutions. Three main strategies for reducing impact are discussed for this product.

- Strategy to reduce water and consumables (foam or soap), predominant in this case is expressed by the groups and ECODESIGN PILOT, SIMAPRO. Curiously, this does not appear explicitly in the group ECOFAIRE.

- The most obvious strategy of reducing and managing raw materials appears in all three groups. However the ECODESIGN PILOT group does not apply this strategy, unlike the other two groups.

- The strategy of influencing user behavior and seeking sustainability is also addressed in all three groups. Two central ideas are discussed. The first is indicating water use to alert the user. The second is working on the removal of hair cut to increase the life span. ECOFAIRE is the only group to propose the addition of an extra function (tooth brush) to better exploit the presence of the handle. In parallel, participants actively and reflectively questioned the acceptability and practicality of this design choice, as well as whether the designer could be seen as legitimate to have a real impact on user behavior, see (Lilley, 2009).

In conclusion, this stage of simplification and prioritization of the environmental problems caused by shaving is addressed homogeneously between the three groups.

Table 9: Implementation of environmental strategies in the shaving case

\begin{tabular}{|c|c|c|c|c|c|c|c|c|}
\hline Tool & Strategy Statement & 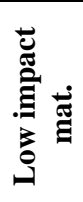 & 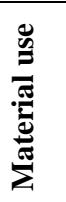 & 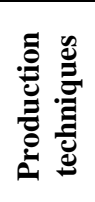 & 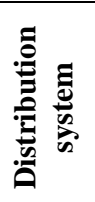 & 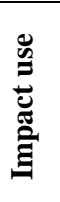 & 芯 & 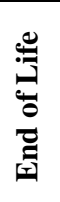 \\
\hline \multirow[t]{3}{*}{ SIMAPRO } & $\begin{array}{l}\text { Limited amount of material } \\
\text { (razor) }\end{array}$ & & $\mathrm{x}$ & & & & & \\
\hline & Reduce water and foam & & $\mathrm{x}$ & & & $\mathrm{x}$ & & \\
\hline & Evacuate water and cut hair & & & & & & $\mathrm{X}$ & \\
\hline \multirow[t]{3}{*}{ ECOFAIRE } & Choose a single material & & $\mathrm{x}$ & & & & & $\mathrm{x}$ \\
\hline & Add Function & & & & & $\mathrm{x}$ & $\mathrm{X}$ & \\
\hline & Remove the handle & & $\mathrm{x}$ & & & & & \\
\hline \multirow{4}{*}{$\begin{array}{l}\text { ECO } \\
\text { DESIGN } \\
\text { PILOT }\end{array}$} & Reduce water consumption & & & & & $\mathrm{x}$ & & \\
\hline & User behavior & & & & & $\mathrm{x}$ & $\mathrm{x}$ & \\
\hline & Minimize: bag, bomb, water & & $\mathrm{x}$ & & & $\mathrm{x}$ & & \\
\hline & Indicate water consumption & & & & & $\mathrm{x}$ & & \\
\hline
\end{tabular}




\subsubsection{Solution finding}

Outcomes from solution finding, summarized in this section, call into question the issue of shaving at various levels. In order to illustrate this point, two researchers recorded and classified the whole set of solutions into four categories (Table 10). The systemic scale of Brezet (1997) was adapted to the shaving context as following: (1) Product improvement deals with optimising the existing product (razor or packaging); (2) Product Redesign deals with a change in product or consumables (soap or foam). (3) Function Innovation relates to the use of the product and consumables, and may require new consumer behaviour; (4) System innovation considers not only the product itself, but also a new system of products. Examples of creative outcomes from the eco-design sessions are provided in Appendix C. Although no statistical analysis can be made on this reduced sample of solutions, it can nevertheless be noted that the tested eco-design tools mainly cater for the first two of these concepts, i.e. product improvement and redesign. Function Innovation can only be found with ECODESIGN PILOT, where a genuine effort was developed by the team to reduce hot water consumption. The other two concepts were more intensively tackled by the fourth tool dedicated to industrial designers, INFORMATION INSPIRATION (Vallet, Millet\& Eynard, 2009; 2011). In conclusion, this analysis confirms that generated ideas call into question a wide range of factors, from a local change of material to a global sustainable management of consumables (water, foam or soap).

Table 10: Number of solutions on different systemic levels

\begin{tabular}{|l|l|c|c|c|}
\cline { 2 - 4 } \multicolumn{1}{c|}{ Tool } & \multicolumn{1}{c|}{ SIMAPRO } & ECOFAIRE & $\begin{array}{c}\text { ECODESIGN } \\
\text { PILOT }\end{array}$ \\
\hline $\begin{array}{l}\text { Level of } \\
\text { Solution }\end{array}$ & Total number of solutions & 9 & 8 & 10 \\
\cline { 2 - 5 } $\begin{array}{l}\text { Product } \\
\text { Improvement }\end{array}$ & $\begin{array}{l}\text { Example of solution } \\
\text { Biodegradable material } \\
\text { Colours from vegetable pigments }\end{array}$ & 4 & 5 & 1 \\
\hline $\begin{array}{l}\text { Product } \\
\text { Redesign }\end{array}$ & $\begin{array}{l}\text { Blow out hair system } \\
\text { Multi-purpose handle } \\
\text { (toothbrush/razor) }\end{array}$ & 5 & 3 & 6 \\
\hline $\begin{array}{l}\text { Function } \\
\text { Innovation }\end{array}$ & $\begin{array}{l}\text { Indication of water consumption } \\
\text { through a change of stiffness of the } \\
\text { razor handle } \\
\text { Gauging plug (to indicate water } \\
\text { consumption and temperature) }\end{array}$ & 0 & 0 & 3 \\
\hline $\begin{array}{l}\text { System } \\
\text { Innovation }\end{array}$ & $\begin{array}{l}\text { Association with organic cosmetic } \\
\text { products }\end{array}$ & 0 & & \\
\hline
\end{tabular}

\section{Main outcomes and discussion}

As a reminder, the intent of this paper is to characterize the eco-design activities with regard to traditional design practice. Subsection 4.1 will examine the first hypothesis H1, which stated that " The eco-design process has a similar structure to a traditional design process ". In subsection Erreur ! Source du renvoi introuvable., the second hypothesis $\mathrm{H} 2$ is discussed, i.e. "All activities are not equally important in time spent. Eco-design can be differentiated from design when the more important activities are considered".

A clear distinction is made between what appears to be within this experiment, 'tool-dependent' and 'tool-independent' eco-activities. Finally the limits of the study are underlined.

\subsection{Nature of the eco-design process}

In order to investigate the nature of the eco-design process performed by experienced eco-designers in conceptual design, we have been coding three sessions. The coding model, adapted from a traditional design model by Stempfle \& Badke-Schaub (2002) was successfully implemented. Hence it can be concluded that the three eco-design processes have a similar nature to a traditional design process. Moreover the three eco-activities highlighted by the literature survey have been recognized throughout the coding process. More precisely, most of the time is spent by experts on initial environmental assessment (30.9\% on average) final environmental assessment (13.9\% on average) and solution finding (13.6\%). Time spent on strategy definition is a long way behind, with $3.9 \%$ on average. After this first step of validation, it is relevant to discuss the relative importance of eco-activities and their support by eco-design tools. 


\subsection{Relative importance of on eco-activities and influence of eco- design tools}

The investigation of our second hypothesis involved the implementation of three distinct eco-design tools with different environmental scopes or objectives (cf. 2.1). The influence of tools appears to depend on the considered eco-activity. It was observed that, apart from ECOFAIRE, experts choose to freely tackle the eco-design issue in the first stage of work, and implement the assigned tool after $1 / 3$ and $2 / 3$ of total time for ECODESIGN PILOT and SIMAPRO respectively. It is assumed that the initial 'tuning' phase of the eco-design process relies on the sharing of the expertise of the participants. This leads us to define 'tool-independent activities' which are achieved thanks to environmental expertise.

Alternatively some activities are exclusively supported by tools, and the relative importance of the activities (in time spent) is dependent on the type of tool as follows.

\subsubsection{Eco-activities fostered by the tested tools}

The hypothesis $\mathrm{H} 2$ leads to compare the effective performance of eco-design tools against the 'Content' categories with their expected performance from the literature survey.

SIMAPRO is expected to be most efficient in environmental assessment, whether initial or final. The protocol reveals that it covers most of the assessment of solutions, and unexpectedly about $20 \%$ of the solutions finding. It would also be expected to help with initial assessment, but this was conducted quite independently from the tool by the participants, relying on their previous expertise.

ECOFAIRE should, in theory, equally foster all eco-design activities thanks to the various dedicated sheets. In practice it was used for three activities in the main: initial assessment, solution finding and environmental assessment of solutions. ECODESIGN PILOT is expected to be most appropriate for environmental strategy definition and solution finding. This is partly verified since the observed contribution of the tool deals with solution finding and environmental assessment of solutions. The findings of this section are summarized in Table 11.

Table 11: Eco-design activities covered by tested eco-design tools

\begin{tabular}{|c|c|c|c|c|}
\hline \multirow[t]{3}{*}{ Tool } & \multicolumn{4}{|c|}{ Eco-design activity } \\
\hline & \multicolumn{2}{|c|}{$\begin{array}{l}\text { Environmental } \\
\text { assessment }\end{array}$} & \multirow[t]{2}{*}{ Solution finding } & \multirow[t]{2}{*}{$\begin{array}{c}\text { Environmental } \\
\text { Strategy }\end{array}$} \\
\hline & $\begin{array}{l}\text { Initial } \\
\text { assessment }\end{array}$ & $\begin{array}{l}\text { Assessment } \\
\text { of solutions }\end{array}$ & & \\
\hline \multicolumn{5}{|l|}{ SIMAPRO } \\
\hline expected & $\mathrm{x}$ & $\mathrm{X}$ & & \\
\hline observed & & $\mathrm{x}$ & $\mathrm{X}$ & \\
\hline \multicolumn{5}{|l|}{ ECOFAIRE } \\
\hline expected & $\mathrm{X}$ & $\mathrm{x}$ & $\mathrm{X}$ & $\mathrm{x}$ \\
\hline observed & $\mathrm{x}$ & $\mathrm{x}$ & $\mathrm{X}$ & \\
\hline \multicolumn{5}{|l|}{ ECODESIGN PILOT } \\
\hline expected & & & $\mathrm{X}$ & $\mathrm{x}$ \\
\hline observed & $\mathrm{x}$ & $\mathrm{x}$ & & \\
\hline
\end{tabular}

The three tools influence the transactions between experts in distinct ways. With ECOFAIRE, the main focus is on the creation of value for the company. Several moments of dialogue hint at the consumer's perception ("Wait, a green guy would never buy anything disposable") or leading companies' strategic position towards disposable razors. This is in line with the targeted end-users of the tool: eco-design consultants. The approach of ECODESIGN PILOT is based on a hypothetical quantitative assessment of water and material consumption. It can be noted that this group did not use the 'Assistant' module on the first phase of environmental analysis. This module was either not identified by subjects, or not required because of sufficient knowledge on their part. The systematic search for solutions which followed gave rise to a large number of solutions. Of these the team leader chose to make a detailed representation of 4 concepts out of 10. Lastly, and probably with the aim of greater efficiency, the use of SIMAPRO is characterized by a low level of interactions. Nevertheless, the SIMAPRO group tends to implement a greater number of steps of the eco-design process. The group goes beyond the proposition of several environmental concepts to achieve a simplified evaluation of the scenarios created collectively. 


\subsubsection{Tool-independent eco-activities: environmental assessment and environmental strategy definition}

Throughout the experiment, the first activity not supported by tools appears to be the initial environmental assessment. Our assumption that this activity is part of the eco-designers' expertise seems to be confirmed by a comment from the first questionnaire: "I have the feeling that functional aspects were tackled by questioning directly the product rather than using the tool". The detailed analysis provided in 3.2.1. leads to another conclusion, being the approach is based on an 'ecofunctional' way of assessing product performances. In our view, the identification of a stage of ecofunctional assessment is consistent with the results of Reymen, Dorst \& Smulders (2009) concerning the co-evolution of problem-solution involving several players at design stages. The notion of usage appears as a "bridging concept" between the problem space and possible solutions, and the creation of detailed usage scenarios is an illustration of this. We were also faced with a difficulty of separating functional from environmental discussions. Indeed, the conditions of use of the razor is a bridge between these two views. The intersection of environmental, functional but also aesthetic and market criteria by eco-experienced designers had already been pointed out by Bakker (1995) during the solution assessment stage, the initial assessment being initially performed quite rapidly. Our hypothesis is that the presence of several designers forces the construction of a shared vision from the outset. This however requires a much longer and more thorough initial assessment phase calling into play the various different viewpoints.

The second activity not supported by tools is the environmental strategy definition. As it is addressed in the same way between the three groups, it seems to lead to the conclusion that, for this product, expressing environmental strategies is part of the eco-designer's knowledge. User's behavior is taken into account as expected in 0 .

The proposition is to represent the eco-design activities in order to introduce a balance between environmental assessment, solution finding and strategy (Figure 5). Taking one step further, such a combination may refer to a FBS structure (Gero \& Kannengiesser, 2004) where environmental strategy stands for Function, whereas environmental assessment and solution finding stand for Behavior and Solution respectively. This could be a track for refining the proposed coding scheme.

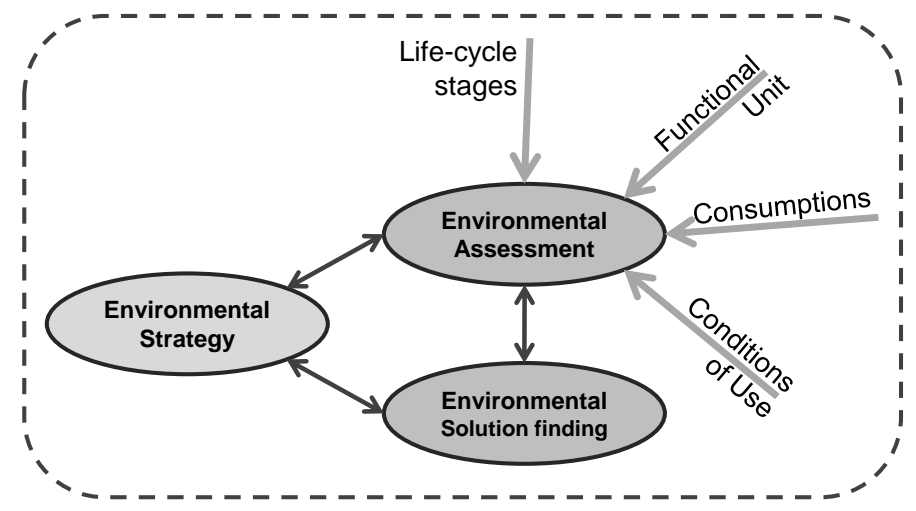

Figure 5: Balance between environmental assessment, solution finding and strategy

\subsection{Limits of the study}

Several limits to this study should be noted. The main limitation is due to the absence of a control group performing the task without the help of any eco-design tool. The control group would have been a useful contribution to ascertain that "When the tool is not used, the main influence in solving the task is due to the expertise of designers". Expected results would have been, in this case, to see subjects spend about 5\% of time on Goal Definition and Environmental strategy, 30\% on Initial Assessment. Moreover, the actual content of environmental strategies and assessment of a control group should have been consistent with what was emphasized in 3.2.1 and 3.2.2.

Our analysis is based on the hypothesis of the influence of a tool on the activity. Yet in design, there are three main factors of influence on the activity: the supporting tool, but also the designers' mindset, or experimental bias (Blessing \& Chakrabarti, 2009). The following limits can also be found in Dwarakanath \& Blessing (1996), who conducted a similar kind of study in a traditional design context. They emphasized limits attributed to: (1) the experimental environment; (2) the experimental protocol; (3) the limited number of cases; (4) the design brief; (5) the subjects. Some advantages of a laboratory environment against an industrial environment have already been pointed out. But it has to be 
underlined that in a lab setting, the eco-design problem becomes a 'stand-alone' task, which might limit the motivation and involvement of subjects.

The choice of a protocol analysis based on group work raises the issue of dealing with parallel activities, whereas transcripts have a linear structure. Moreover, silent actions such as calculations operated in the SIMAPRO team do not appear in the analysis. Evidence of this phenomenon is the reduced number of SIMAPRO transcription lines compared to other tools.

This is a 'small scale' experiment as defined in Cash, et al. (2012), which involves a single test with only a few groups. One can legitimately wonder whether the subjects are a fair representation from across experienced eco-designers. One possible response is to characterize as carefully as possible the participants' profile, i.e. their general eco-design expertise and the previous knowledge of the tool they use.

In addition, it is assumed that, due the simplicity of the product, eco-design experts would prefer to use their previous knowledge than spend time implementing a tool. In further research work, the influence of the control variable 'simplicity of the redesigned product' should be taken into account. Moreover, we focus on a specific typology of product involving deeper discussions on the use phase than on other phases of the life cycle. This may encourage the 'eco-functional' assessment analysed in 3.2.1. As a consequence, it should be mentioned that this work shows observed trends as main outcomes, and more research is necessary to draw general conclusions.

\section{Conclusions and future work}

In this article we first defined the steps of an eco-design approach and showed the main supporting features of the eco-design activity provided by methods and tools. In order to better understand the nature and singularity of eco-design compared to design, participant observation was implemented in three groups of experienced eco-designers, followed by transcription and coding of the verbal transactions. The originality of this approach lies in the simultaneous consideration of several steps within a redesign process. Outcomes from literature usually focus on one specific step, but rarely on the whole eco-design process.

The results of this enquiry validated the hypothesis H1. According to the observation protocol, the ecodesign process is very similar to a traditional design process as far as structure is concerned. This was expected since many of the experts involved have a design background.

As far as H2 is concerned, findings are twofold. Firstly, participants are assumed to rely on their previous expertise to perform initial assessment and strategy definition. Moreover, it has been shown that the initial environmental assessment of the product mixes environmental and functional considerations in qualitative or quantitative usage scenarios. The three groups produced adequate environmental strategies homogeneously.

Secondly, the use of eco-design tools mostly benefits goal definition, solution finding and final assessment. Nevertheless some slight differences between expected and observed performances of ecodesign tools in supporting eco-activities can be reported.

It was intended to shed light on the nature and singularity of eco-design. Does the practice of ecodesign imply more than just learning to use new tools and adding a few environmental criteria to a classical design process?

If the idea to narrow the scope of design through defining a strategy is not original, the basic culture of designers does not allow them to know which lever is really efficient for environmental improvement. Seemingly good ideas (e.g. a change in materials) might not greatly improve the performance, or might even be detrimental. In the case of shaving, considering water consumption is not obvious although it is the main environmental impact throughout the entire life cycle of a razor. New support tools to train designers with strategy definition should be investigated. These could be based on case-studies. As for solution finding, it is a typical eco-activity should we take into account the wide range of solutions observed in 3.2.3. We have demonstrated that solutions range from 'micro' improvements in changing materials to 'macro' changes in water management systems, shaving being only part of the issue. The importance of the user's behavior should be emphasized in cases like this one, leading designers to know more about real usage and consumption patterns than they usually do. As a consequence, solutions derived from insights on usage should be fostered by future eco-design tools.

From this empirical research, it is our opinion that integrating the environmental dimension underpins several major challenges. Those are demanding in time, involvement and require a new holistic sense of design. We have emphasized several key issues: the predominant initial environmental assessment (in time spent) based on one or several relevant functional scenarios; the variety of environmental strategies depending on the type of product and the multi-level search for environmental improvement concepts. 
In a short term perspective, it is envisaged to enrich this work by analyzing eco-design meetings with novices and beginners. The aim is to characterize key eco-design competences involving the state of expertise of designers. We thus hope to contribute to the "new design knowledge" advocated by (Manzini, 2009) by educating a new generation of designers to be aware of the challenges facing a sustainable society.

\section{Acknowlegments}

The authors express their gratitude to the experts who participated in the experiment during the 4th seminar of the national network of researchers in Eco-design of systems for Sustainable Development (EcoSD) held in March 2009 in Paris. Sincere thanks go to Nadège Troussier for her support, and to the reviewers for their meaningful comments.

\section{References}

Akermark A.M. (2005). The Crucial Role of the Designer in EcoDesign. PhD Thesis. Stockholm, Sweden: Royal Institute of technology, KTH.

Badke-Schaub P., Goldschmidt G., Meijer M. (2007). Cognitive conflict in design teams: competing or collaborating. In Proceedings of International Conference on Engineering Design, ICED'07, 28-31 August. Paris, France.

Bakker C. (1995). Environmental Information for Industrial Designers. PhD Thesis. Delft: Delft University of Technology.

Baumann, H., Boons, F., Bragd, A. (2002). Mapping the green product development field: engineering, policy and business perspectives. Journal of Cleaner Production, 10, 409-425.

Blessing L., Charkrabarti A.(2009). DRM, A Design Research Methodology, London: Springer Verlag Ltd.

Brezet J.C., Van Hemel C. (1997). Eco-design-A promising approach to sustainable production and consumption. UNEP, United Nations Publications.

Cash P., Elias E., Deconinck E., Culley S. (2012). Methodological insights from a rigorous small scale design experiment. Design Studies 33(2), 208-235.

Collado D., Ostad-Ahmad-Ghorabi H. (2010). Influence of environmental information on creativity. Design Studies 31, 479-498.

Cross N. (1997). Descriptive modes of creative design: application to an example. Design Studies 18, 427-440.

Cross N. ed (2008). Engineering Design Methods-Strategies for Product Design. 4th edition. Chichester: Wiley \& Sons.

Cruhl M., Diehl J. (2009). Design for sustainability, a step-by-step approach. UNEP, United Nations Publications.

Dorst K. (2001). Creativity in the design process: co-evolution of problem-solution. Design Studies 22, 425-437.

Dwarakanath S., Blessing L. (1996). Ingredients of the Design Process: a Comparison between group and individual work. In Cross N., Christiaans H., Dorst K. Eds, Analysing Design Activity,. John Wiley, Chichester, 93-116.

ECOFAIRE (2008). Methological tool ECOFAIRE, from ECOFAIRE program directed by « SEM régionale des Pays de Loire » and granted by State, Pays de Loire region and ADEME.

Eder, W.E. (2009). Design engineering and needs for methodology. In Proceedings of the International Conference on Engineering Design, ICED’09, 24-27 August. Palo Alto, CA, USA.

Fargnoli M., Kimura F. (2006). Sustainable Design of Modern Industrial Products. In Proceeding of International Conference of Life Cycle Engineering, LCE 2006, 189-194. Leuven, Belgium.

Fargnoli M., Kimura F. (2007). An integrated approach for the sustainability measure of industrial products in design stages. In Proceedings of the International Conference on Engineering Design, ICED'07, 28-31 August. Cité des Sciences et de l'Industrie, Paris, France.

Fuad-Luke A. (2004). The eco-design handbook-A complete sourcebook for the home an office. Second Edition, London: Thames \& Hudson Ltd. 
Fussler C., James P. (1996). Driving Eco Innovation-A breakthrough discipline for innovation and sustainability. London: Pitman Publishing, Pearson Professional Ltd.

Gero, J.S., Mac Neill T. (1998). An approach to analysis of design protocol. Design Studies 19, 21-61.

Gero J.S., Kannengiesser U. (2004). The situated function-behaviour-structure framework. Design Studies 25(4) 373-391.

Goldschmidt G., Sever A.L. (2009). From text to design solution: inspiring design ideas with texts. In Proceedings of the International Conference on Engineering Design, ICED’09, 24-27 August. Palo Alto, CA, USA.

ISO 14040 (1997). Environmental Management. Life Cycle Analysis. Principles and framework. ISO, Geneva, September 1997.

ISO/TR 14062 (2002). Environmental Management, Integrating environmental aspects into product design and development. Technical Report, ISO, Geneva.

ISO 26000: 2010 (2010). Lignes Directrices relatives à la responsabilité sociétale. ISO, Geneva, November 2010.

Jones, E. (2001). Applying structured methods to Eco-innovation. An evaluation of the Product Ideas Tree Diagram. Design Studies 22, 519-542.

Jones, E. (2003). Eco-innovation: tools to facilitate early-stage workshops. PhD Thesis. Brunel: Brunel University.

Knight P., Jenkins J.O. (2009). Adapting and Applying eco-design techniques: a practitioners perspective. Journal of Cleaner Production, 17, 549-558.

Kruger C. (2006). Solution driven versus problem driven design: strategies and outcomes. Design Studies 27 (5) 527-548.

Lagerstedt J, Luttropp C., Lindfors L.G. (2003). Functional Priorities in LCA and Design for Environment. International Journal of Life Cycle Assessment 8(3), 160-166.

Le Pochat S., Bertoluci G., Froelich D. (2007). Integrating ecodesign by conducting changes in SMEs. Journal of Cleaner Production, 15(7), 671-680.

Liikanen LA. (2009). Exploring problem decomposition in conceptual design among novice designers. Design Studies 30, 38-59.

Lilley D. (2009). Design for sustainable behaviour: strategies and perceptions. Design Studies Vol 30 (6), 704-720.

Lindhal M. (2005). Engineering designers' requirements on design for environment methods and tools. $\mathrm{PhD}$ Thesis. Royal Institute of Technology-KTH, Stockholm.

Lindhal M. (2006). Engineering designers' experience of design for environment methods and tools-Requirement definitions from an interview study. Journal of Cleaner Production 14, 487-496.

Lofthouse V.A. (2001). Facilitating Ecodesign in an Industrial Design Context: An Exploratory Study. PhD Thesis. Cranfield University, Cranfield.

Luttrop C., Lagerstedt J. (2006). Ecodesign and the Ten Golden Rules: generic advice for merging environmental aspects into product development. Journal of Cleaner Production, Volume 14, 1396-1408.

Manzini E. (2009). Viewpoint-New Design Knowledge. Design Studies 30, 4-12.

Mc Donnell J., Llloyd P. (2009). About: Designing-Analysing Design Meetings. Netherlands: CRC Press/Balkema.

Millet D. (Dir.) (2003). Intégration de l'environnement en conception-L'entreprise et le développement durable, Paris: Hermès Lavoisier.

Mulet, E. Lopez-Mesa, B., Gonzalez, M.C., Camelo, D. (2007). Characterization of designer interactions in the creative design process. In Proceedings of International Conference on Engineering Design, ICED'07, 28-31 August. Paris, France : Cité des Sciences et de l'Industrie.

Pahl G., Beitz W, Feldhusen J., Grote K.H. (2007). Engineering design-A Systematic Approach, Third Edition. London: Springer-Verlag. 
Pamminger R., Huber M., Wimmer W. (2007). Ecodesign toolbox for the development of green product conceptsCase study digital voice recorder. In Proceeding of the International Conference on Engineering Design, ICED'07, Paris, August 2007, pp. 437-447.

PRé Consultants (2010). SimaPro 7.0, Introduction to LCA. Available online: http//www.presustainability.com/content/manuals, November 2010. Accessed 12/01/12.

Prudhomme G., Pourroy F., Lund K. (2007). An empirical study of engineering knowledge dynamics in a design situation. Journal of Design Research, 6 (3), 333-358.

Reymen I., Dorst K., Smulders F. (2009). Co-evolution in Design Practice. In Mc Donnell J., Llloyd P., About: Designing-Analysing Design Meetings (pp 67-82). Netherlands: CRC Press/Balkema.

Ritzen S. (2000). Integrating Environmental Aspects into Product Development-Proactive Measures. PhD Thesis. Stockholm: Royal Institute of Technology-KTH.

Sakao T., Paulsson S. Mizuyama H. (2011). Inside a PSS Design Process: Insights through Protocol Analysis. In Proceeding of the International Conference on Engineering Design, ICED'11, Copenhagen, August 2011.

Sauer J., Wiese B., Ruttinger B. (2002). Improving ecological performance of electrical consumer products: the role of design-based measures and user variables. Applied Ergonomics 33, 297-307.

Schmalz J., Boks C (2011). Simutaneous Application of Design for Sustainable Behavior and Linked Benefit Strategies in Practice. In Proceeedings of 18th CIRP International Conference on Life Cycle Engineering, LCE 2011, May 2nd-4th 2011. Braunschweig, Germany.

Stempfle J., Badke-Schaub P. (2002). Thinking in Design Teams- An Analysis of Team Communication. Design Studies 23, 473-496.

Tyl B., Legardeur J., Millet D., Vallet F., Stimulate creative ideas for eco-innovation: an experiment to compare eco-design and creativity tools. IDMME Virtual Concept 2010, 20-22 October. Bordeaux, France.

Valkenburg, R., Dorst, K. (1998). The reflective practice of design teams. Design Studies 19(3), 249-271.

Vallet F., Millet D., Eynard B. (2009). Investigating the use of eco-design guides: presentation of two case studies. In Proceedings of the International Conference on Engineering Design, ICED'09, 24-27 August. Palo Alto, CA, USA.

Vallet F., Millet D., Eynard B. (2011). Requirements and Features Clarifying for eco-design tools. In Global Product Development. Springer, A. Bernard Ed., 127-137. Nantes, France.

Wever R., Van Kuijk J., Boks C. (2008). User-centred design for sustainable behavior. International Journal of Sustainable Engineering 1(1), 9-20.

Yong, S.K., Sang, W.L., Jung A.P., Ji, Y.J. (2009). Exercises for cognitive elements of design creativity. In Proceedings of the International Conference on Engineering Design, ICED'09, 24-27 August. Palo Alto, CA, USA.

Wimmer W., Züst R. (2003). Ecodesign PILOT: product investigation, learning and optimization tool for sustainable product development. Kluwer Academic Publishers, Dordrecht, Netherlands. 


\begin{tabular}{|c|c|c|c|}
\hline Step & Code & Description & Examples \\
\hline $\begin{array}{l}\text { Goal } \\
\text { clarification }\end{array}$ & $\mathbf{G}$ & $\begin{array}{l}\text { Definition of context } \\
\text { Choice of product } \\
\text { Innovation level } \\
\text { Labels, current legislation }\end{array}$ & $\begin{array}{l}\text { «We choose a man's razor » } \\
\text { «It is a new product or a minor innovation?" } \\
\text { «EACH will come up ». }\end{array}$ \\
\hline $\begin{array}{l}\text { Initial } \\
\text { assessment }\end{array}$ & $\begin{array}{r} \\
\text { M } \\
\text { FA } \\
\text { T } \\
\text { FV }\end{array}$ & $\begin{array}{l}\text { Environmental assessment of } \\
\text { existing product } \\
\text { Conditions of shaving: number of } \\
\text { passages, shaving surface, frequency, } \\
\text { security, handling... } \\
\text { Functional Unit, function, boundaries } \\
\text { of study } \\
\text { Consumptions } \\
\text { (water, consumable, packaging), waste } \\
\text { Raw materials } \\
\text { Production } \\
\text { Distribution Logistics } \\
\text { End of Life }\end{array}$ & $\begin{array}{l}\text { «That is to say } 7 \text { faces account for } 2 \text { legs in surface » } \\
\text { «We shave through once, twice» } \\
\text { «What product do we consider? The razor, the associated consumables? » } \\
\text { « About use, setting the boundaries is difficult enough as it is so, if you add logistics-» } \\
\text { «Three sprays of foam a year, sold » } \\
\text { «What is important, tepid water } 40^{\circ} \mathrm{C}, \text { it's a lot of energy. In my opinion the impact is a lot } \\
\text { also. » } \\
\text { "Let's say } 2 \mathrm{~g} \text { of cardboard for you [MEN], } 3 \mathrm{~g} \text { of sachet for us [WOMEN]» } \\
\text { «This one maybe it is not polystyrene, maybe a polypropylene» } \\
\text { «In a preliminary phase, there must be lamination » } \\
\text { « Here I am reading 'Made in USA, conditioned in Europe'. Distances seem enormous, but with } \\
\text { shipping -» } \\
\text { « About metal, is there any reprocessing in closed loop ?» }\end{array}$ \\
\hline Strategy & $\mathbf{S t}$ & $\begin{array}{l}\text { Proposition concerning strategies et } \\
\text { priorities of environmental } \\
\text { improvement }\end{array}$ & $\begin{array}{l}\text { Increase durability by all means » } \\
\text { «Reduce water consumption » } \\
\text { «On the cycle : transport and packaging are negligible » }\end{array}$ \\
\hline $\begin{array}{l}\text { Generation } \\
\text { of solutions }\end{array}$ & So & $\begin{array}{l}\text { Proposition concerning solutions } \\
\text { and ideas } \\
\text { Analogy }\end{array}$ & $\begin{array}{l}\text { "You can imagine a pump, a syringe » } \\
\text { «It is like spreading. Just what is needed to cut» }\end{array}$ \\
\hline
\end{tabular}




\begin{tabular}{|c|c|c|c|}
\hline $\begin{array}{l}\text { Analysis } \\
\text { and } \\
\text { assessment } \\
\text { of } \\
\text { solutions }\end{array}$ & $\mathbf{E S}$ & $\begin{array}{l}\text { Questions/answers concerning the } \\
\text { solution space } \\
\text { Exploration of space, } \\
\text { Conditions of validity } \\
\text { Assessment of solutions } \\
\text { (environmental, functional) } \\
\text { qualitative or quantitative. }\end{array}$ & $\begin{array}{l}\text { "But by the way the razor could also be the blade protection device » } \\
\text { "If the width of the blade is increased, less shaving time is necessary, but are we going } \\
\text { everywhere? } \\
\text { "Maybe it is the same for water. Nevertheless as far as wastes are concerned- } \\
\text { «The risk is that the customer might say we don't want it » }\end{array}$ \\
\hline Decision & D & Decision for or against an idea & « Let's say the change of lubricant, I, am suppressing it because it is ridiculous» \\
\hline Control & $\mathbf{C}$ & Reflexion on a solution & « Not stupid » \\
\hline Other & $\mathbf{O}$ & $\begin{array}{l}\text { Approval } \\
\text { Digression on another topic }\end{array}$ & $\begin{array}{l}\text { «Yes », « No », « OK » } \\
\text { «It is like with my students ...» }\end{array}$ \\
\hline
\end{tabular}

Appendix A: Definition of 'Content' codes

\begin{tabular}{|c|c|c|c|}
\hline Steps & Code & Description & Examples \\
\hline Planning & PI & $\begin{array}{l}\text { Proposition concerning the } \\
\text { organization of the group', } \\
\text { Reading items of tools }\end{array}$ & $\begin{array}{l}\text { «Need to have ideas» } \\
\text { "It would be interesting to represent those ideas. I'm afraid that the one who is going to go } \\
\text { through our records - Make a quick sketch on the paperboard» } \\
\text { «We could use Eco-design Wheel R1 and Check-list R2 » }\end{array}$ \\
\hline Analyze & $\mathbf{A}$ & $\begin{array}{l}\text { Questions/answers concerning } \\
\text { process or tool }\end{array}$ & «Does that mean it has not been done yet if we say 'realization no'?» \\
\hline Evaluation & $\mathbf{E}$ & $\begin{array}{l}\text { Evaluation of process: } \\
\text { Negative } \\
\text { Positive } \\
\text { Critique of design brief } \\
\text { Time management }\end{array}$ & $\begin{array}{l}\text { «We shouldn't be going in every direction» } \\
\text { «This we know » «We answered correctly in fact» } \\
\text { «It's a } 10 \text { month-study in fact» } \\
\text { « Are we late on schedule? } »\end{array}$ \\
\hline Decision & D & Decision concerning process & «So we'll do without [SIMAPRO]» \\
\hline Control & $\mathbf{C}$ & $\begin{array}{l}\text { Summary, reformulation, reflecting } \\
\text { on group's work } \\
\text { Reporting work }\end{array}$ & $\begin{array}{l}\text { «I am summarizing » } \\
\text { «I am reminding you of levers» }\end{array}$ \\
\hline Other & $\mathbf{O}$ & $\begin{array}{l}\text { Social relations, jokes } \\
\text { Ask to repeat }\end{array}$ & \begin{tabular}{|l|} 
«e careful what you say» \\
«You can show? » «What you say?»
\end{tabular} \\
\hline
\end{tabular}

Appendix B: Definition of 'Process' codes 
Appendix C: Examples of creative outcomes

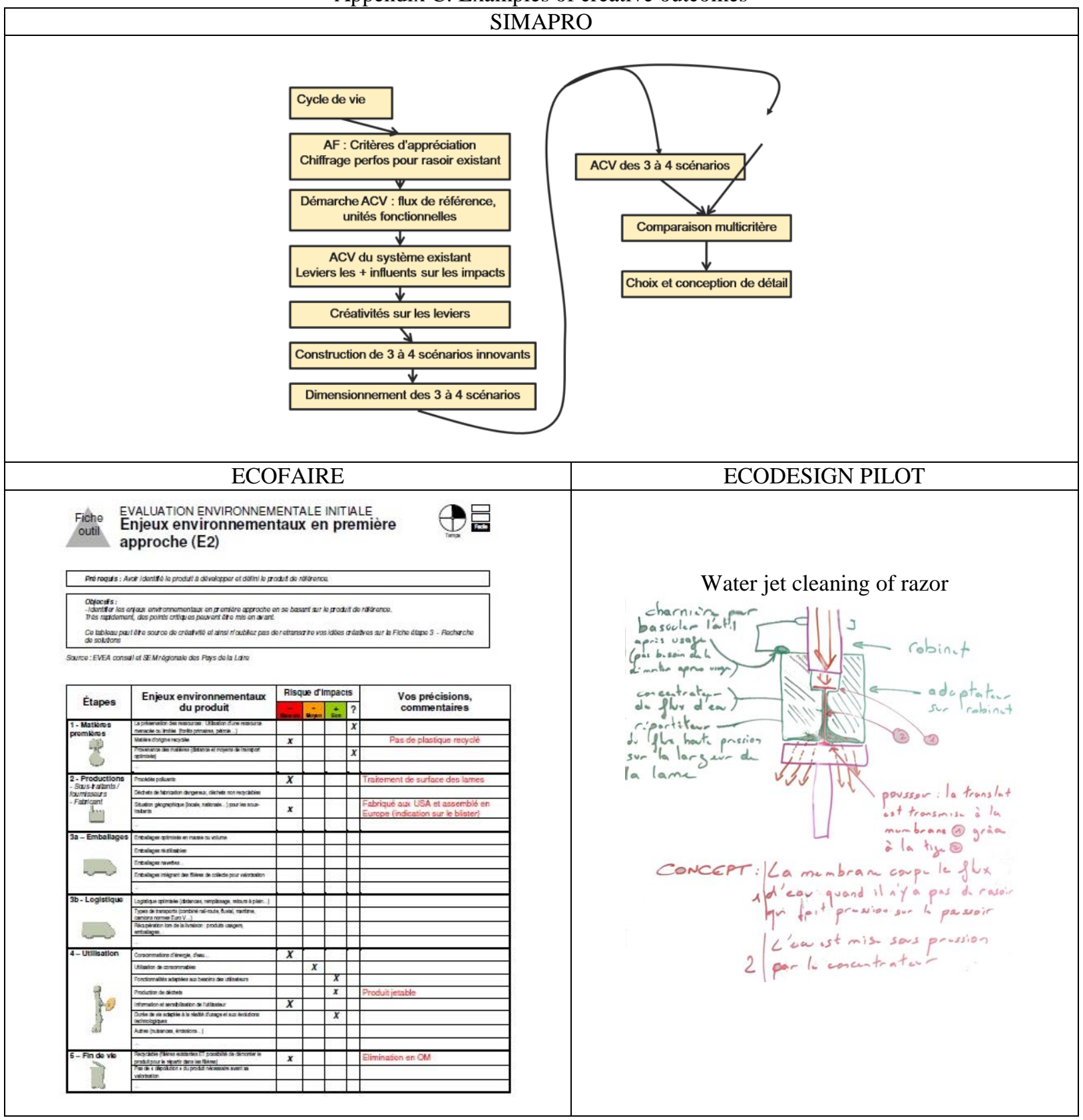

